\title{
MICROSTRUCTURAL CHARACTERIZATION OF Cu82.3AI8.3Mn9.4 SHAPE MEMORY ALLOY AFTER ROLLING
}

\author{
Mirko Gojićl ${ }^{*}$, Stjepan Kožuh ${ }^{1}$, Ivana Ivanić ${ }^{1}$, Magdalena Selanec ${ }^{1}$, Tamara \\ Holjevac Grgurićl, Borut Kosec ${ }^{2}$, Diana Ćubela ${ }^{3}$, Omer Beganović ${ }^{4}$ \\ ${ }^{1}$ University of Zagreb, Faculty of Metallurgy Sisak, Aleja narodnih heroja 3, \\ 44103 Sisak, Croatia, \\ ${ }^{2}$ University of Ljubljana, Faculty of Natural Science and Engineering, \\ Aškerčeva 12, 1000, Ljubljana, Slovenia, \\ ${ }^{3}$ Faculty of Metallurgy and Materials Science, Travnička cesta 1, 72000 \\ Zenica, $B \& H$, \\ ${ }^{4}$ Metallurgical Institute "Kemal Kapetanović”, Travnička cesta 7, 72000 \\ Zenica, $B \& H$
}

Received 25.08.2017

Accepted 27.09.2017

\begin{abstract}
In this paper, the microstructure of Cu82.3A18.3Mn9.4 (in wt. \%) shape memory alloy after hot and cold rolling was investigated. The Cu82.3Al8.3Mn9.4 alloy was produced by a vertical continuous casting method in the form a cylinder rod of $8 \mathrm{~mm}$ in diameter. After the casting, hot and cold rolling was performed. By hot rolling a strip with a thickness of $1.75 \mathrm{~mm}$ was obtained, while by cold rolling a strip with a thickness of $1.02 \mathrm{~mm}$ was produced. After the rolling process, heat treatment was performed. Heat treatment was carried out by solution annealing at $900{ }^{\circ} \mathrm{C}$ held for 30 minutes and water quenched immediately after heating. The microstructure characterization of the investigated alloy was carried out by optical microscopy (OM), scanning electron microscopy (SEM) equipped with a device for energy dispersive spectroscopy (EDS). Phase transformation temperatures and fusion enthalpies were determined by differential scanning calorimetry (DSC) method. The homogenous martensite microstructure was confirmed by OM and SEM micrographs after casting. During rolling the two-phase microstructure occurred. Results of DSC analysis showed martensite start $\left(\mathrm{M}_{\mathrm{s}}\right)$, martensite finish $\left(\mathrm{M}_{\mathrm{f}}\right)$, austenite start $\left(\mathrm{A}_{\mathrm{s}}\right)$ and austenite finish $\left(\mathrm{A}_{\mathrm{f}}\right)$ temperatures.
\end{abstract}

${ }^{*}$ Corresponding author: Mirko Gojić, gojic@simet.hr 
Keywords: Shape memory alloy (SMA); continuously casting; microstructure; heat treatment; rolling.

\section{Introduction}

Shape memory alloys (SMAs) are relatively new metallic materials which show the ability to return to some previously defined shape when subject to the appropriate treatment. It is a result of the reversible martensitic phase transformation. The main types of these alloys are nitinol (Ni-Ti), Cu-based and Fe-based alloys [1-3].

These alloys are interesting in numerous commercial engineering applications. There is a high demand for SMAs with high strength and shape memory effect in technical applications [2]. The main advantages of Cu-based alloys are their low price, relatively simple fabrication procedure, and high electrical and thermal conductivity compared to other shape memory alloys. The $\mathrm{Cu}-\mathrm{Al}-\mathrm{Ni}$ and $\mathrm{Cu}-\mathrm{Al}-\mathrm{Zn}$ alloys are extensively investigated [4-6]. However, they are brittle and susceptible to intergranular fracture. The $\mathrm{Cu}-\mathrm{Al}-\mathrm{Mn}$ shape memory alloy is proposed due to better ductility and good strain recovery. The reason for higher ductility of $\mathrm{Cu}-\mathrm{Al}-\mathrm{Mn}$ shape memory alloys can be correlated to decreasing the degree of order of the $\beta$ parent phase [7,8]. Addition of manganese to $\mathrm{Cu}$-based SMAs stabilizes the $\beta$ parent phase and improves the ductility of the alloys [9]. The other advantages of $\mathrm{Cu}-\mathrm{Al}-\mathrm{Mn}$ alloys compared to other $\mathrm{Cu}$-based SMAs are higher shape memory strain, the larger recovery power, better ductility and higher damping capacity. The addition of manganese increases the binding force between the constituent atoms leading to the increased activation energy for diffusion and decreased diffusion rate of the atom for re-ordering [10].

Generally, SMAs are fabricated by casting procedure followed by plastic working (rolling or drawing) including heat treatment. Continuous casting technique as one of the SMA production technologies increases in past years, due to the special competitive growth mechanism of crystals and continuously cast products with a favorable texture formation $[11,12]$. In this paper, the microstructure of continuously casted $\mathrm{Cu} 82.3 \mathrm{Al} 8.3 \mathrm{Mn} 9.4$ shape memory alloys after hot and cold rolling as well as after heat treatment (quenching and aging) was compared.

\section{Experimental}

The Cu82.3Al8.3Mn9.4 alloy (Table 1) used in this research was prepared by melting pure elements $(99.9 \% \mathrm{Cu}, 99.8 \% \mathrm{Mn}$, and $99.5 \% \mathrm{Al}$, wt. \%) in a vacuum induction furnace under protective argon atmosphere. Firstly, the ingot $(\phi 110 \mathrm{~mm} \times 180$ $\mathrm{mm}$ ) was produced by graphite mold casting. The ingot was then re-melted in the same furnace and continuously cast. The continuously casted strand (cylindrical bar with 8 $\mathrm{mm}$ diameter) of the alloy was obtained using the device for the vertical continuous casting which is connected with the vacuum induction furnace. Solid bars were produced directly from the $13.15 \mathrm{~kg}$ melt. Starting temperature of the melt was $1250{ }^{\circ} \mathrm{C}$. The process of re-melting was performed in vacuum (2-4) $\times 10^{-1} \mathrm{mbar}$. During casting, the pressure of argon protective atmosphere was set around 500 mbar. Casting speed was $290 \mathrm{~mm} / \mathrm{min}$.

Table 1. The chemical composition of Cu-Al-Mn alloy, wt. \%.

\begin{tabular}{ccc}
\hline $\mathrm{Cu}$ & $\mathrm{Al}$ & $\mathrm{Mn}$ \\
\hline 82.3 & 8.3 & 9.4 \\
\hline
\end{tabular}


Casted rods (diameter of $7.7 \mathrm{~mm}$ ) were inserted in the chamber furnace at $900{ }^{\circ} \mathrm{C}$ and heated for 5 minutes. After that, rods were hot rolled in the light section rolling mill up to strip width $13.8 \mathrm{~mm}$ and thickness of $1.75 \mathrm{~mm}$ (Table 2). The heating time was 5 minutes until $5.4 \mathrm{~mm}$, then 3 minutes for thickness from 3.5 to $1.75 \mathrm{~mm}$. The hot rolled strips with a thickness of $1.75 \mathrm{~mm}$ were heated at $880{ }^{\circ} \mathrm{C}$ for 1 minute and then cold rolled. Cold rolling of hot rolled strips was carried out by cold rolling mill LOMA (Table 3). After cold rolling, the strip with width $13.9 \mathrm{~mm}$ and thickness $1.02 \mathrm{~mm}$ was obtained. After hot and cold rolling, heat treatment of strips was performed in laboratory electro-resistance furnace. Solution annealing of samples was carried out at $900{ }^{\circ} \mathrm{C}$ for 30 minutes, followed by cooling in water.

Table 2. Parameters of hot rolling.

\begin{tabular}{|c|c|c|c|c|}
\hline $\begin{array}{l}\text { Number } \\
\text { of } \\
\text { rolling } \\
\text { passes }\end{array}$ & $\begin{array}{l}\text { Rod diameter/ } \\
\text { Strip height } \\
\text { (mm) }\end{array}$ & $\begin{array}{l}\text { Rod width } \\
\text { /strip after } \\
\text { pass } \\
(\mathrm{mm}) \\
\end{array}$ & $\begin{array}{c}\text { Individual reduction } \\
\text { of height (reduction } \\
\text { of height per pass) } \\
(\%)\end{array}$ & $\begin{array}{c}\text { Furnace } \\
\text { temperature } \\
\text { before rolling } \\
\text { pass }\left({ }^{\circ} \mathrm{C}\right)\end{array}$ \\
\hline- & 7.7 & 7.7 & - & - \\
\hline 1. & 7.0 & 8.1 & 9.1 & 895 \\
\hline 2. & 6.3 & 8.4 & 10.0 & 893 \\
\hline 3. & 5.4 & 8.5 & 14.3 & 890 \\
\hline 4. & 4.4 & 9.4 & 18.5 & 895 \\
\hline 5. & 3.5 & 10.3 & 20.5 & 886 \\
\hline 6. & 2.2 (two passes) & 13.0 & 37.1 & 880 \\
\hline 7. & 1.75 & 13.8 & 20.5 & 880 \\
\hline
\end{tabular}

*Measurement error: $0.01 \mathrm{~mm}$

Table 3. Parameters of cold rolling.

\begin{tabular}{lccc}
\hline $\begin{array}{l}\text { Number } \\
\text { of rolling } \\
\text { passes }\end{array}$ & $\begin{array}{c}\text { Strip height } \\
(\mathrm{mm})\end{array}$ & $\begin{array}{c}\text { Individual reduction of } \\
\text { height } \\
\text { (reduction of height per } \\
\text { pass) }(\%)\end{array}$ & $\begin{array}{c}\text { Total reduction of height } \\
\text { (reduction relative to starting } \\
\text { height of } 1.75 \mathrm{~mm}),(\%)\end{array}$ \\
\hline- & 1.75 & - & - \\
1. & 1.60 & 8.6 & 8.6 \\
2. & 1.54 & 3.8 & 12.0 \\
3. & 1.47 & 4.5 & 16.0 \\
4. & 1.43 & 2.7 & 18.3 \\
5. & 1.34 & 6.3 & 23.4 \\
6. & 1.29 & 3.7 & 26.3 \\
7. & 1.20 & 7.0 & 31.4 \\
9. & 1.11 & 7.5 & 36.6 \\
10. & 1.02 & 8.1 & 41.7 \\
\hline
\end{tabular}

*Measurement error: $0.01 \mathrm{~mm}$

The specimen microstructure was characterized by optical microscopy $(\mathrm{OM})$ and scanning electron microscopy (SEM) equipped with energy dispersive spectroscopy (EDS). The SEM was operated by Secondary electron detector (SE), at an acceleration 
voltage of $20 \mathrm{kV}$. Calibration for the quantitative measurements was performed by $\mathrm{Au}$ standard. Samples were ground (from 120 to 1000 grade paper) and polished $(0.3 \mu \mathrm{m}$ $\mathrm{Al}_{2} \mathrm{O}_{3}$ ) before microstructural investigation. Further on, the samples were etched in a solution of $\mathrm{FeCl}_{3}$, methanol, and $\mathrm{HCl}$.

Differential Scanning Calorimeter Mettler Toledo 822e was performed to determine phase transformation temperatures of hot and cold rolled $\mathrm{Cu}-\mathrm{Al}-\mathrm{Mn}$ alloys. Dynamic heating/cooling measurements were conducted in a temperature range from $50{ }^{\circ} \mathrm{C}$ to $250{ }^{\circ} \mathrm{C}$, with a rate of $10{ }^{\circ} \mathrm{C} / \mathrm{min}$, in a nitrogen atmosphere. The rate of 10 ${ }^{\circ} \mathrm{C} / \mathrm{min}$ is standard heating/cooling rate for DSC dynamic measurements. Generally, temperature calibration was performed by heating calibration substances with wellknown melting temperatures above their melting point and recording the resulting DSC curve. The calibration point used was the extrapolated onset of the melting peak since it is independent of the specimen mass and can be determined easily. Indium (having a melting temperature of $156.6^{\circ} \mathrm{C}$ ) is often used as a reference, and in our investigation, we used In. Generally, one of error is the experimental determination of the melting point using the extrapolated onset of the DSC melting curve. Whereas some calibration materials have very well-defined onset points because of their rather linear slope of the melting curve, others can show pre-melting or have uneven slopes that do not permit an exact onset extrapolation.

\section{Results and discussion}

Continuously casted $\mathrm{Cu} 82.3 \mathrm{Al} 8.3 \mathrm{Mn} 9.4$ alloy shows martensite microstructure with grain boundaries, clearly identified by OM (Fig. 1a). After rolling the microstructure is changed. Fig. 2a shows microstructure of strip after hot rolling, while Fig $2 \mathrm{~b}$ shows microstructure after cold rolling. In all samples, there is an evident twophase microstructure. After cold rolling, all forms of the crystals show a deformation of a lower or greater degree due to cold deformation. In the $\beta$-crystals, there is a more pronounced martensite form. The overall impression is that the microstructure of the initial casting state is intensely and inhomogeneously deformed during cold deformation. Crystals are further deformed in the direction of deformation as well as $\beta$ crystals that still show an additional transformation in martensite of a smaller or greater extent.
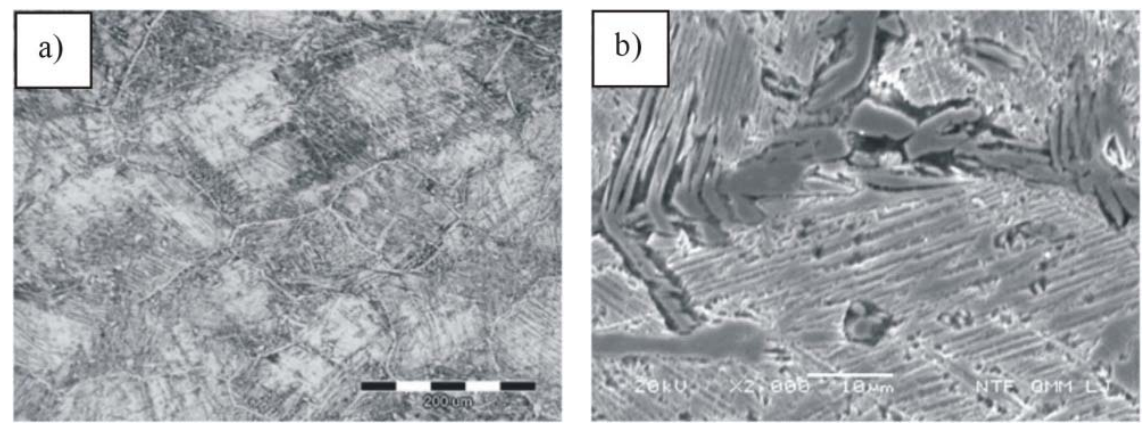

Fig. 1. Optical micrograph (a) and SEM micrograph (b) of the Cu82.3Al8.3Mn9.4 alloy after continuous casting. 

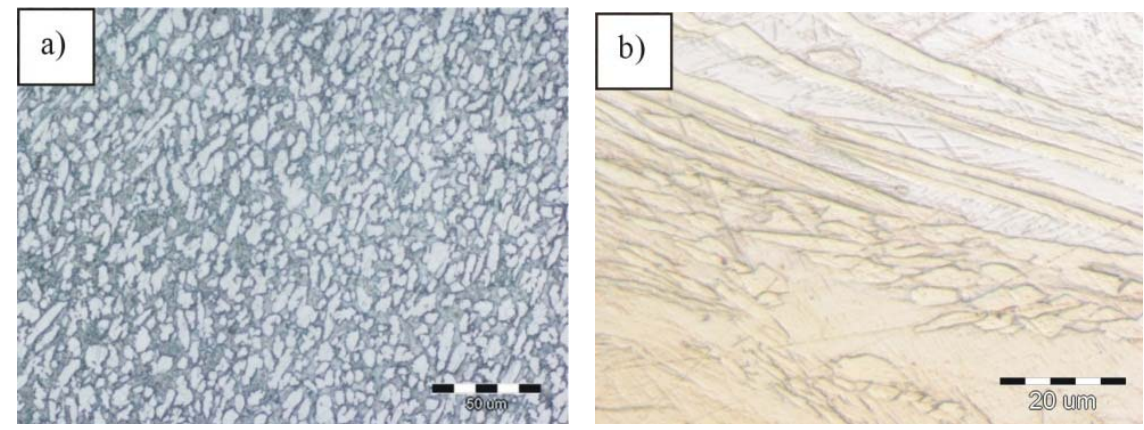

Fig. 2. Optical micrographs of Cu82.3Al8.3Mn9.4 alloy after hot rolling (a) and after cold rolling (b) at a magnification of 500x.
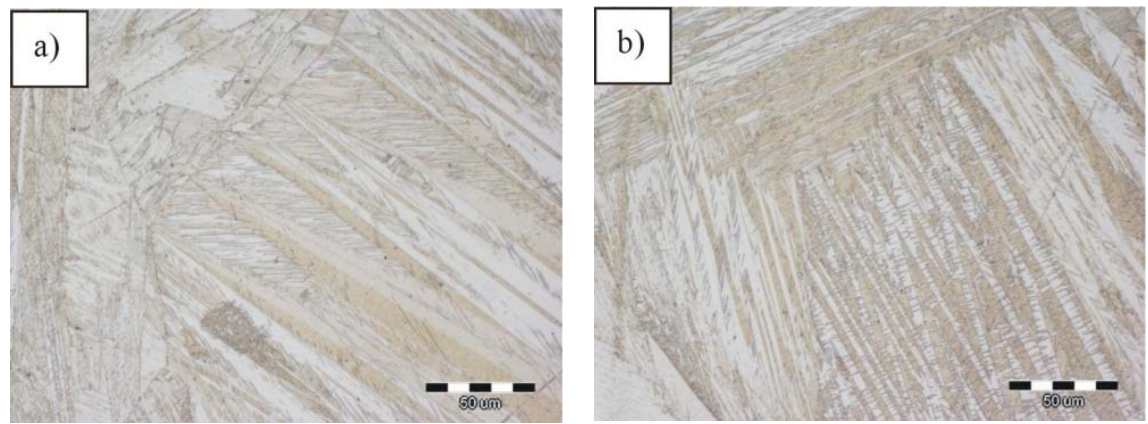

Fig. 3. Optical micrographs of Cu82.3Al8.3Mn9.4 SMA after heat treatment $900{ }^{\circ} \mathrm{C} / 30$ minutes $/ \mathrm{H}_{2} \mathrm{O}$ of the hot rolled strip (a) and cold rolled strip (b), magnification 500x.

Tables 2 and 3 provide an overview of height changes during hot and cold rolling. The displayed deformations up to a thickness of $4.4 \mathrm{~mm}$ refer to the shape of the sample which does not correspond to the cross-section of the strip. Therefore, the height reduction is orientational, i.e. it represents a change in the height of the sample but it can`t be used for a perfectly correct plasticity evaluation due to an irregular crosssection which deviates from a regular rectangular cross-section characteristic of the strip. The height reduction is the largest in the center of the rod, and it is actually reduced closer to the edges of the rod. The surface cracks observed on the rod before rolling were not significantly propagated until the height of the rod was reduced to 5.4 $\mathrm{mm}$. For continuation of rolling of the rods at a reduced risk of major cracks, all four sides of the rods were ground by a hand grinder to eliminate the cracks (visible to the eyes). After the rolling to the thickness of the $4.4 \mathrm{~mm}$ oversides of the first and second rod were grounds again until the elimination of the observed transverse cracks. Table 2 shows the temperature of the furnace before taking out the rods. The actual rolling rod temperatures are lower due to the relatively large distance of the furnace from the rolling mill and the small diameter (thickness) of the rod (strip). After cold reduction of $36.6 \%$, the strip was still very flexible. However, after the $9^{\text {th }}$ pass, when the overall cold deformation reached $41.7 \%$, the strip became considerably less flexible. Cold rolling strip $1.02 \times 13.9 \times 1000 \mathrm{~mm}$ was heated at $880{ }^{\circ} \mathrm{C}$ for 1 minute. The flexibility of the strip was restored without any inclination to the fracture. 
At the temperature of $900{ }^{\circ} \mathrm{C}$, the $\mathrm{Cu} 82.3 \mathrm{Al} 8.3 \mathrm{Mn} 9.4$ alloy has $\beta$ phase with a disordered bcc structure. After solution annealing at $900{ }^{\circ} \mathrm{C}$ and quenching in water, the samples at room temperature contain $\beta_{1}{ }^{\prime}$ martensite and $\beta$ parent phase as can be seen in Figs. 4 and 5. By rapid cooling in water, the alloy undergoes the ordering transitions $\beta(\mathrm{A} 2) \rightarrow \beta 2(\mathrm{~B} 2) \rightarrow \beta 1\left(\mathrm{~L} 22_{1}\right)$ and then martensite transformation $\beta_{1}\left(\mathrm{~L} 2{ }_{1}\right) \rightarrow \beta_{1}{ }^{\prime}$ occurs [13]. During rapid cooling from the stable $\beta$-phase region the martensitic phase occurs below the $\mathrm{M}_{\mathrm{s}}$-temperature. The micrographs include grains and martensite plates (Figs. $4 \mathrm{~b}$ and $5 b)$. The grains appear clearly and martensite plates have different orientations into different grains. The martensite is formed primarily as a needle-like shape. In some parts, a V-shape martensite was noticed. This is typical self-accommodating zig-zag martensite morphology, which is characteristic for the $\beta^{\prime}$ martensite in SMAs. The parallel bands in martensite can be considered twin-like martensite.
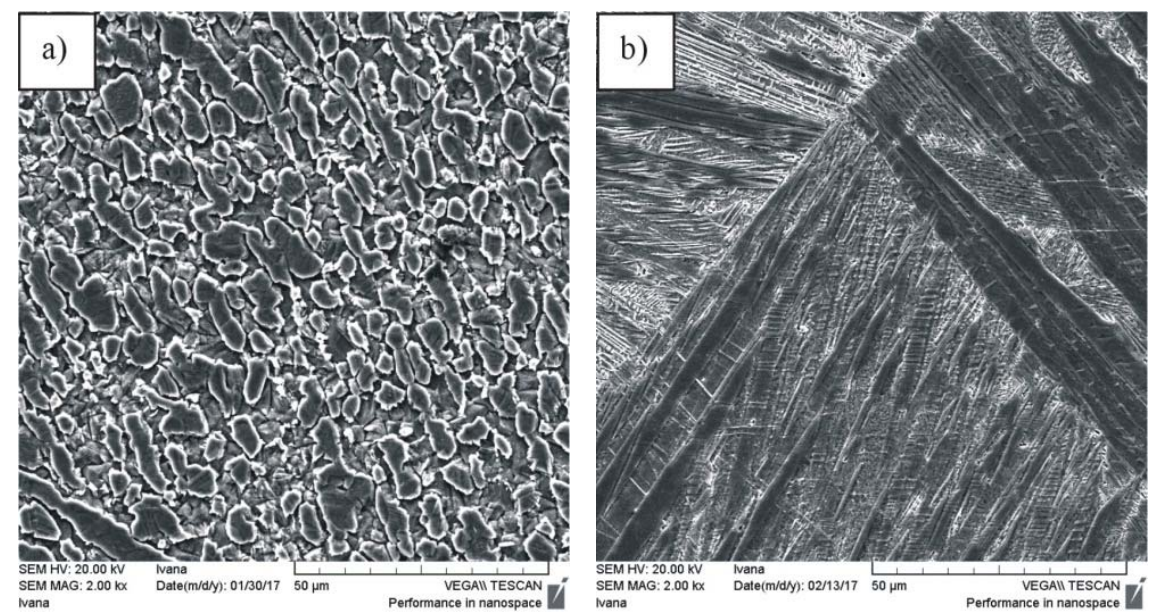

Fig. 4. SEM micrographs of Cu82.3Al8.3Mn9.4 SMA after hot rolling (a) and hot rolling and heat treatment $900{ }^{\circ} \mathrm{C} / 30$ minutes $/ \mathrm{H}_{2} \mathrm{O}(b)$.
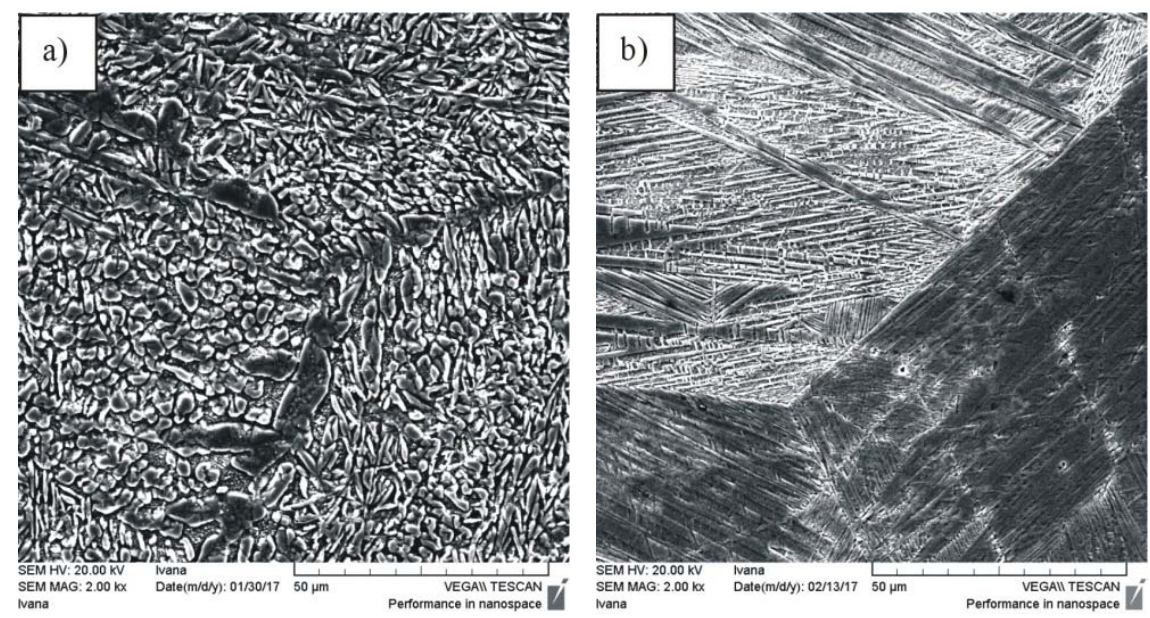

Fig. 5. SEM micrographs of Cu82.3Al8.3Mn9.4 SMA after cold rolling (a) and cold rolling and heat treatment $900{ }^{\circ} \mathrm{C} / 30$ minutes $/ \mathrm{H}_{2} \mathrm{O}(b)$. 
Phase transformation temperatures, as well as enthalpies of $\mathrm{Cu} 82.3 \mathrm{Al} 18.3 \mathrm{Mn} 9.4$ specimens, are listed in Table 4.

Table 4. Phase transformation temperatures, fusion enthalpies and hysteresis of Cu82.3Al8.3Mn9.4 alloys: $A_{s}, A_{f}$-start and finish austenite temperatures, $M_{s}, M_{f}-$ start and finish martensite temperatures, $\Delta H$-enthalpy, $\Delta T_{H}-$ hysteresis.

\begin{tabular}{lcccccc}
\hline Cu-Al-Mn alloy & $\begin{array}{c}\mathrm{A}_{\mathrm{s}} \\
{\left[{ }^{\circ} \mathrm{C}\right]}\end{array}$ & $\begin{array}{c}\mathrm{A}_{\mathrm{f}} \\
{\left[{ }^{\circ} \mathrm{C}\right]}\end{array}$ & $\begin{array}{c}\mathrm{M}_{\mathrm{s}} \\
{\left[{ }^{\circ} \mathrm{C}\right]}\end{array}$ & $\begin{array}{c}\mathrm{M}_{\mathrm{f}} \\
{\left[{ }^{\circ} \mathrm{C}\right]}\end{array}$ & $\begin{array}{c}\Delta \mathrm{H} \\
{[\mathrm{J} / \mathrm{g}]}\end{array}$ & $\begin{array}{c}\Delta \mathrm{T}_{\mathrm{H}} \\
\left(\mathrm{A}_{\mathrm{f}}-\mathrm{M}_{\mathrm{s}}\right) \\
{\left[{ }^{\circ} \mathrm{C}\right]}\end{array}$ \\
\hline Cold-rolled & 40.76 & 50.59 & 51.42 & 35.62 & 0.17 & - \\
& & & & & & \\
Hot rolled and heat treated at & 21.57 & 65.34 & 53.48 & 32.96 & 0.48 & \\
$900^{\circ} \mathrm{C} / 30$ minutes $/ \mathrm{H}_{2} \mathrm{O}$ & & & 19.26 & 2.25 & 0.007 & 11.86 \\
Cold rolled and heat treated at & & & & & & \\
$900^{\circ} \mathrm{C} / 30$ minutes $/ \mathrm{H}_{2} \mathrm{O}$ & 28.85 & 50.56 & 44.29 & 27.37 & 0.23 & 6.27 \\
& & & 8.11 & -8.68 & 0.36 & \\
\hline
\end{tabular}

Results of DSC analysis indicate that hot and cold rolled and heat treated Cu82.3A18.3Mn9.4 alloys show one endothermic peak at the heating curve related to austenitic transformation. Cold rolled alloy has a relatively narrow austenitic transformation, with start transformation temperature, $\mathrm{A}_{\mathrm{s}}=40.76{ }^{\circ} \mathrm{C}$ and finish transformation temperature, $\mathrm{A}_{\mathrm{f}}=50.59{ }^{\circ} \mathrm{C}$. Austenitic transformation becomes wider after heat treating of the $82.3 \mathrm{Cu}-8.3 \mathrm{Al}-9.4 \mathrm{Mn}$ sample at $900{ }^{\circ} \mathrm{C}$ for 30 minutes and quenching in the water, and it starts at significantly lower temperatures, with $\mathrm{A}_{\mathrm{s}}=28.85$ ${ }^{\circ} \mathrm{C}$ and $\mathrm{A}_{\mathrm{f}}=50.56{ }^{\circ} \mathrm{C}$. At cooling DSC curve of the cold rolled sample it can be seen one exothermic peak due to martensitic transformation, with transformation temperatures at $\mathrm{M}_{\mathrm{s}}=51.42{ }^{\circ} \mathrm{C}$ and $\mathrm{M}_{\mathrm{f}}=35.62{ }^{\circ} \mathrm{C}$. Unlike unquenched alloy, both heat treated samples, hot and cold rolled, show two exothermic transformations at cooling DSC curves, which can point to the formation of different martensitic structures after heat treatment at $900{ }^{\circ} \mathrm{C}$ and quench in water. Hot rolled quenched sample shows higher martensitic start temperature in relation to cold rolled sample as well as heat treated alloy. Formation of the first martensitic structure in this sample is more intense, while the other peak is barely detectable (Table 4). Contrary, the cold rolled and heat treated $\mathrm{Cu} 82.3 \mathrm{Al}$ 8.3Mn9.4 alloy both have pronounced martensitic peaks, with transformation temperatures shifted to lower temperatures (Figure 6, Table 4). Martensitic transformation enthalpies are also higher and confirm the intensive formation of martensitic structure in the quenched cold rolled Cu82.3A18.3Mn9.4 alloy (Table 4). After cold rolling and heat treatment of Cu82.3A18.3Mn9.4 alloy, hysteresis decreases due to the thermoelastic martensitic transformation (Table 4). The existence of two martensitic structures, what is indicated by DSC analysis of quenched samples, should be also confirmed by other techniques, such as XRD or TEM analysis. 


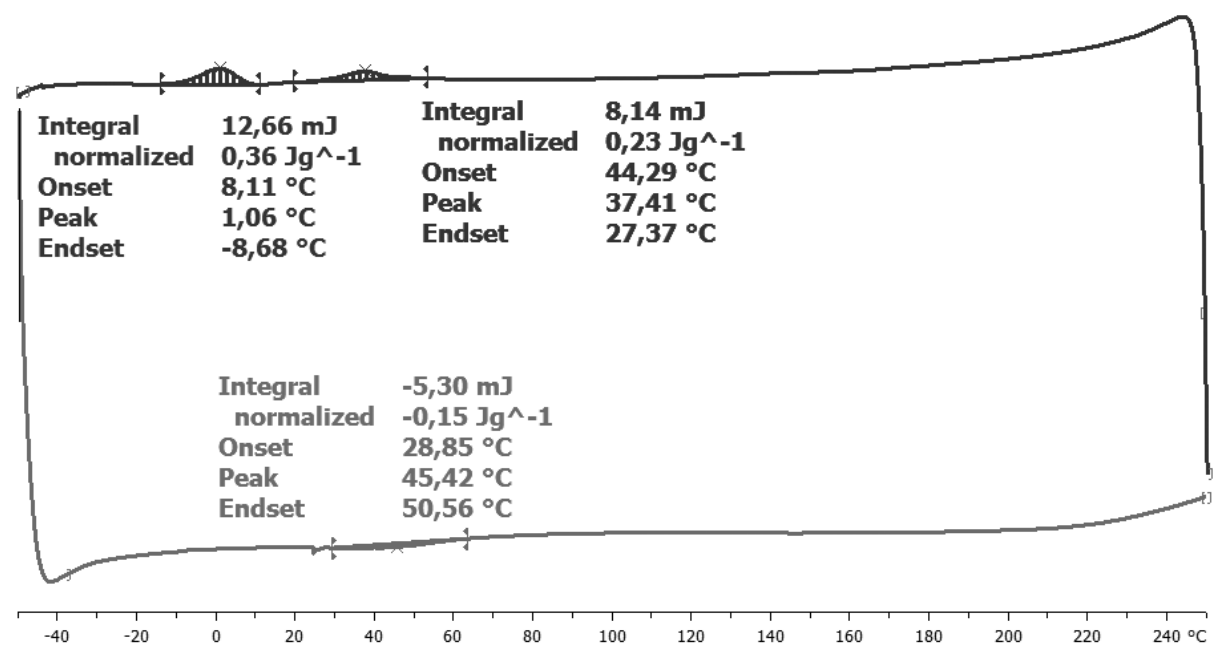

Fig. 6. DSC thermogram of cold rolled and heat treated Cu82.3Al8.3Mn9.4 alloy.

\section{Conclusion}

After continuous casting, the $\mathrm{Cu} 82.3 \mathrm{Al}$ (8.3Mn9.4 shape memory alloy shows martensite microstructure. During hot and cold rolling there is two-phase microstructure. After cold rolling, the crystals are elongated in the direction of rolling and martensite microstructure exists. By quenching in water $\beta_{1}{ }^{\prime}$ martensite is obtained where martensite plates have different orientation into grains. Results of DSC analysis showed endothermic peaks at heating curves with corresponding austenitic transformation. During cooling, the DSC results showed exothermic plates due to martensitic transformation.

\section{Acknowledgements}

This work has been fully supported by Croatian Science Foundation under the project (IP-2014-09-3405).

\section{References}

[1] C. Lexcellent, Shape-memory Alloys Handbook. New York, John Wiley\&Sons 2013.

[2] J. M. Jani, M. Leary, A. Subic, M. A. Gibson: Mater Des, 56 (2014) 1078-1113.

[3] D. Corić, M. Franz: Zavarivanje, 5-6 (2007) 179-187.

[4] G. Lojen, I. Anžel, A.C. Kneissl, A. Križman, E. Unterweger, B. Kosec, M. Bizjak: J Mater Process Technol, 162-163 (2005) 220-229.

[5] W. Huang: Mater Des, 23 (2002) 11-19.

[6] S. Zeghdane, K. Necib, A. Britah: EPJ Web of Conferences, 6 (2010) 1-9, http://dx.doi.org/10.1051/epjconf/20100629001

[7] R. Kainuma, S. Takahashi, K. Ishida: Metall Mater Trans A, 27A (1996) 21872195.

[8] M.R. Rezvani, A. Shokuhfar: Mater Sci Eng A, 532 (2012) 282-286. 
[9] U.S. Mallik, V. Sampath: J Alloys Compd, 469 (2009) 156-163.

[10] J. Chen, Z. Li, Y.Y. Zhao: J Alloys Compd, 480 (2009) 481-484.

[11] G. Lojen, A.C. Kneissl, M. Gojić, R. Rudolf, M. Čolić, I. Anžel: Livarski vestnik, 57 (2010) 172-193.

[12] M. Gojić, L. Vrsalović, S. Kožuh, A.C. Kneissl, I. Anžel, S. Gudić, B. Kosec, M. Kliškić: J Alloys Compd, 509 (2011) 9782-9790.

[13] Y.Q. Jiao, Y.H. Wen, N. Li, J.Q. He, J, Teng: J Alloys Compd, 491 (2010) $627-$ 630.

(C) C) Creative Commons License

This work is licensed under a Creative Commons Attribution 4.0 International License. 